\title{
Long-Period Secular Variations of the Earth's Magnetic Field Revealed by Pacific Deep-Sea Sediment Cores
}

\author{
Takaharu SATO $^{1}$ and Kazuo KOBAYASHI ${ }^{2}$ \\ ${ }^{1}$ Faculty of Technology, Niigata University, Igarashi, Niigata 950-21, Japan \\ ${ }^{2}$ Ocean Research Institute, University of Tokyo, Nakano-ku, Tokyo 164, Japan
}

(Received April 6, 1988; Revised August 6, 1988)

\begin{abstract}
Close correlation of the variations in saturation isothermal remanent magnetization (SIRM) is found between two deep-sea sediment cores with different sedimentation rates, which were sampled $500 \mathrm{~km}$ apart from each other. The clear correlation of the variations of the natural remanent magnetization (NRM) to SIRM in the relative inter-core time scale obtained from the SIRM correlation, and the rock magnetic diagnosis for the sediments, indicate that the variations probably reflect secular variation of the geomagnetic field intensity in almost the whole length of the Quaternary period. Long period secular variation of declination ranging from 0.02 My to the order of $0.1 \mathrm{My}$ is revealed from a comparison of the relative declination between the cores in the early Brunhes epoch. The width of magnetizing zone, represented by half fixing depths, is estimated by comparing deconvoluted variations in declination and NRM/SIRM.
\end{abstract}

\section{Introduction}

Knowledge of the characteristics of the secular variation for various time ranges is of obvious importance in producing magnetohydrodynamic models of the earth's magnetic field. In addition to observatory records and archaeomagnetism, recent paleomagnetic studies on lake sediments supply sufficient data to construct models for the secular variation of time ranges up to about 10,000 years (CREER and TUCHOLKA, 1983). However, there are a few duplicate records of the secular variation with a longer time range (KULIKOVA, 1984; KAWAI et al., 1977). Difficulties in the studies on secular variation by use of the Quaternary deep-sea sediments are brought about by insufficient inter-core correlation methods and by fairly wide possible magnetizing zones which are generally presumed and accepted, in which the natural remanent magnetization of the sediments is acquired.

In the present study, the data from the natural remanent magnetization (NRM) of two deep sea sediment cores with different rates of sedimentation are compared on the basis of the correspondence of SIRM logs found in these cores. In order to examine the reliability of the data in the records of the paleomagnetic field, the degree of correspondence of the data from the NRM is tested, and the widths of the magnetizing zone are estimated from the closest resemblances in the deconvoluted 
variations.

2. Cores Used and Magnetic Measurements in This Study

Two piston cores studied here, KH73-4-7 (core A), and KH 73-4-8 (core B), were collected in the western equatorial Pacific Ocean (Fig. 1, Table 1) by the R/V Hakuho Maru. Sediments in cores A and B are wholly composed of calcareous ooze. A few mottles and rings of slightly different colors are seen in the sections of split cores. No evidence of mechanical disturbance is observed except for short portions near the top and at the bottom (about $1 \mathrm{~m}$ each) (KOBAYASHI et al., 1980).

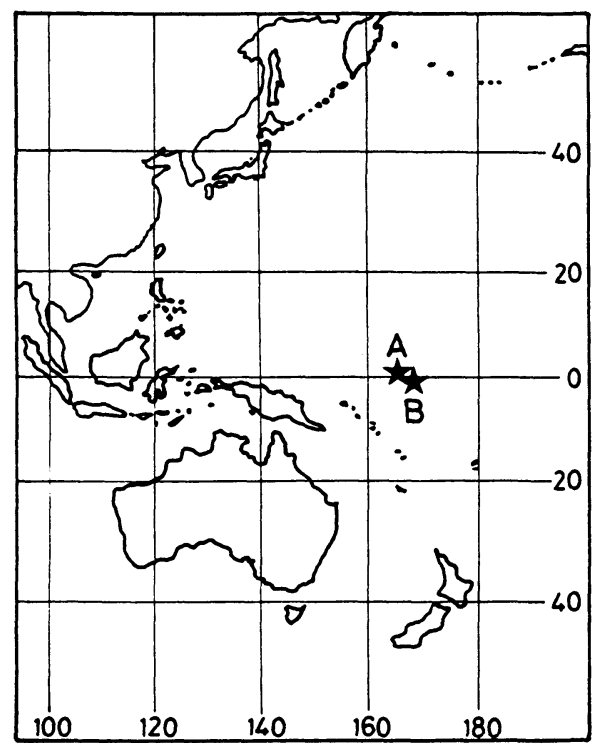

Fig. 1. Geographic locations of two core sites, KH 73-4-7 and KH 73-4-8.

Table 1. Site locations of two cores used in the study.

\begin{tabular}{lcc}
\hline Core & A (KH 73-4-7) & B (KH 73-4-8) \\
Position & $2^{\circ} 41.3^{\prime} \mathrm{N}$ & $1^{\circ} 33.2^{\prime} \mathrm{S}$ \\
& $164^{\circ} 50.2^{\prime} \mathrm{E}$ & $167^{\circ} 38.6^{\prime} \mathrm{E}$ \\
$\begin{array}{l}\text { Water } \\
\text { depth (m) }\end{array}$ & 4,160 & 4,000 \\
$\begin{array}{l}\text { Core } \\
\text { length }(\mathrm{m})\end{array}$ & 11.27 & 10.58 \\
\hline
\end{tabular}


Thin sections of $2.4 \times 2.4 \times 0.43 \mathrm{~cm}$ were successively prepared from the cores, and the direction and intensity of NRM were measured using a spinner magnetometer. The procedure of preparation and measurement is described by KAWAI et al. (1976). As the cores were taken at the equatorial region, paleomagnetic inclination is very small. In the present study, only magnetic declination and intensity were analysed as paleomagnetic parameters.

The stability of NRM was tested by partial demagnetization under decreasing alternating fields (a.f.) with a peak value up to 400 Oe. Figure 2 shows a.f. demagnetization curves for specimens from core B. An appreciably large unstable component appears to exist in the upper $113 \mathrm{~cm}$ of the core. However, no significant changes are observed in the direction of remanent magnetization vectors. The normally magnetized specimens from the lower part of the core are stable, with a median destructive field of approximately 250 Oe. The reversely magnetized specimens exhibit an initial increase in intensity as well as change in direction after demagnetization by a small field (weaker than $100 \mathrm{Oe}$ ). In higher fields, however, no appreciable change is observed in the direction of magnetization. This behavior is attributed to removal of a secondary component acquired in the direction parallel to the present geomagnetic field.

Results of the stability test confirm that the present cores contain an unstable component of magnetization which can be removed by an alternating field weaker than 100 Oe. The stability of core A has already been tested (KAWAI et al., 1976, 1977; SUEISHI et al., 1979). The NRM of the specimens is highly stable with a median destructive field of around $250 \mathrm{Oe}$. Consequently, an alternating field of 100 Oe was applied for the routine cleaning of the NRM of these cores.

From successive sequences of core B, one of every two specimens was selected and magnetized in a static field of 9,000 Oe. Saturation isothermal remanent magnetization (SIRM) thus acquired was measured and compared to the same measurements previously taken from core A. Figure 3 shows the results of core B, obtained from the present work, together with the previous data. The gradual shift in the declination seen in core $B$ is presumably due to a horizontal rotation of the corer during the coring operation or from a twisting of the sediment during extraction from the corer. The results for core A (KAWAI et al., 1976, 1977; SUEISHI et al., 1979) are compiled in Fig. 4. The high frequency components in the variation of the SIRM intensity contribute to a much lesser extent than to the NRM intensity. To calculate the ratio of NRM/SIRM for both cores, the intensity of SIRM was estimated by interpolation for the samples for which the SIRM was not measured.

\section{Age Determination of Several Horizons of the Cores}

\subsection{Magnetic polarity boundaries}

Reversals in magnetic directions are clearly seen in the cores. The BrunhesMatuyama boundary, and the upper and lower boundaries of the Jaramillo and Olduvai events, are distinctly recognized in both cores. These horizons can thus be correlated precisely between the two cores. Sedimentation rates of the polarity 

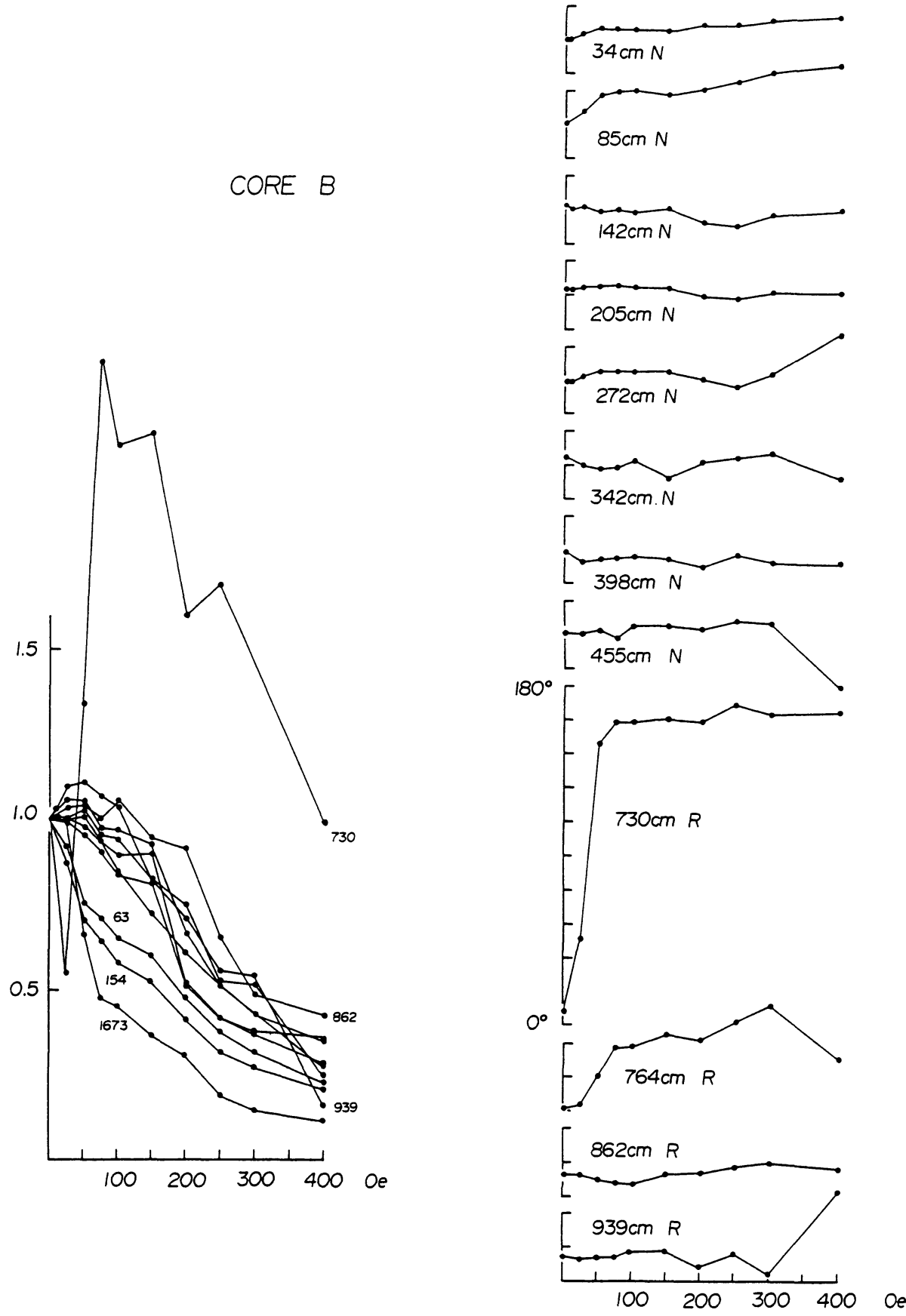

Fig. 2. a.f. demagnetization curves of core B. Numbers indicate depths in the core $(\mathrm{cm})$. 


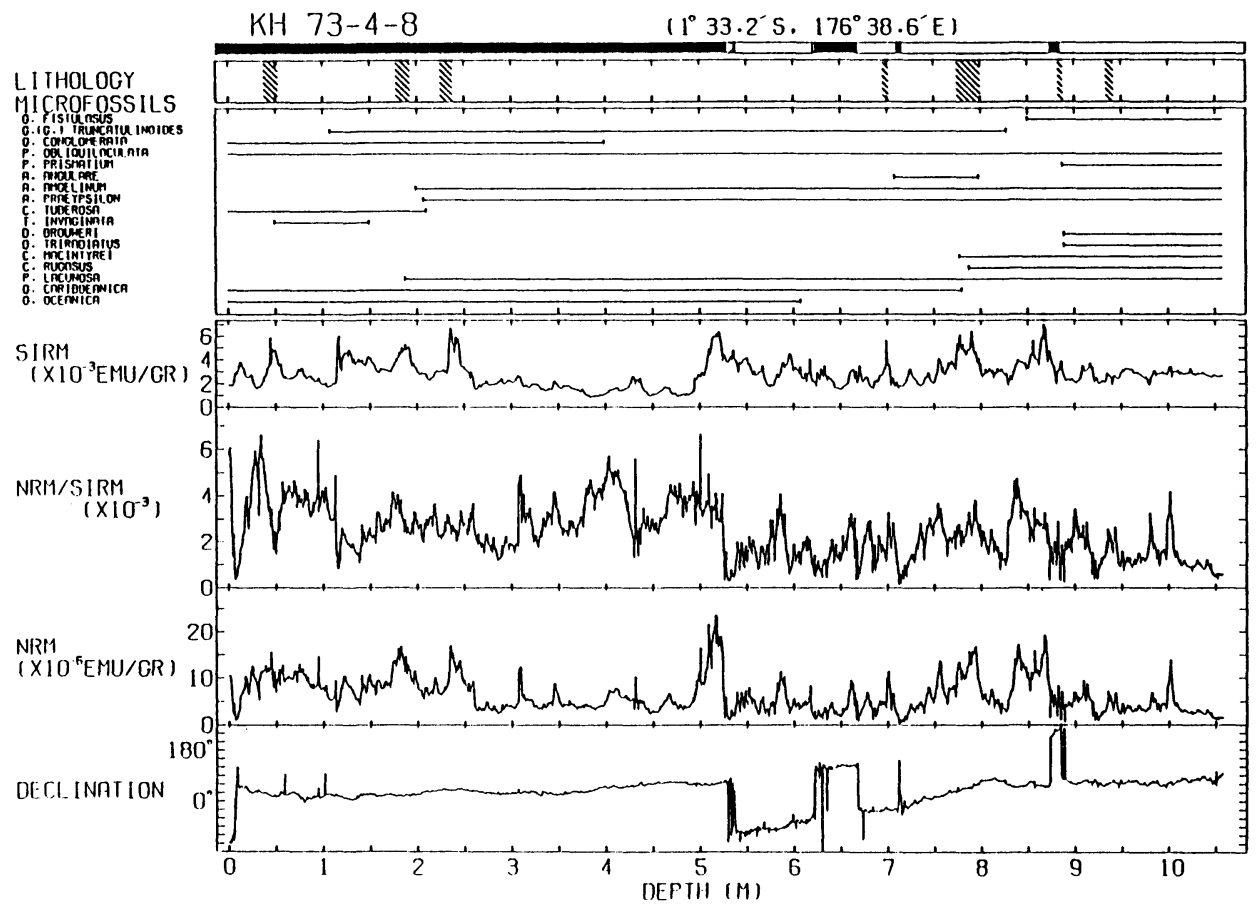

Fig. 3. Results from core B. Data by KAWAI et al. (1977) and SuEISHI et al. (1979) are also included. Faunal and floral stratigraphy are referred from the results by TAKAYANAGI et al. (1979). Dark portions observed in the core by KOBAYASH et al. (1980) are hatched in the column of lithology.

interval of each core, estimated from the polarity time scale, are quite different from one another. The rate for the Matuyama epoch in core A is nearly constant but those in core B fluctuated largely.

\subsection{Paleontological and ESR studies}

Several micropaleontological events characterized by the first and last occurrences of taxa in these cores were reported by TAKAYANAGI et al. (1979), as shown in Figs. 3 and 4. They showed that the stratigraphic relationship of $G$. (G.) truncatulinoides datum with $G$. caribbeanica datum and $A$. angulare datum in core $B$ is reversed of the standard sequences. They inferred that it may be due to a secondary deposit or bioturbation in part of core B. The last appearance of $P$. lacunosa, which presumably occurred at the isotope stage 12 (ca. $0.474 \mathrm{My}$ ) (GARTNER, 1977), is observed at $125 \mathrm{~cm}$ in core A and $180 \mathrm{~cm}$ in core B. As seen in Fig. 6, the depth of the last appearance in core B is correlated with about $107 \mathrm{~cm}$ in core $A$. That is $18 \mathrm{~cm}$ shallower than that in core $A$. So the age at $116 \mathrm{~cm}$ in core $A$ is assumed to be $0.474 \mathrm{My}$ in this paper. 


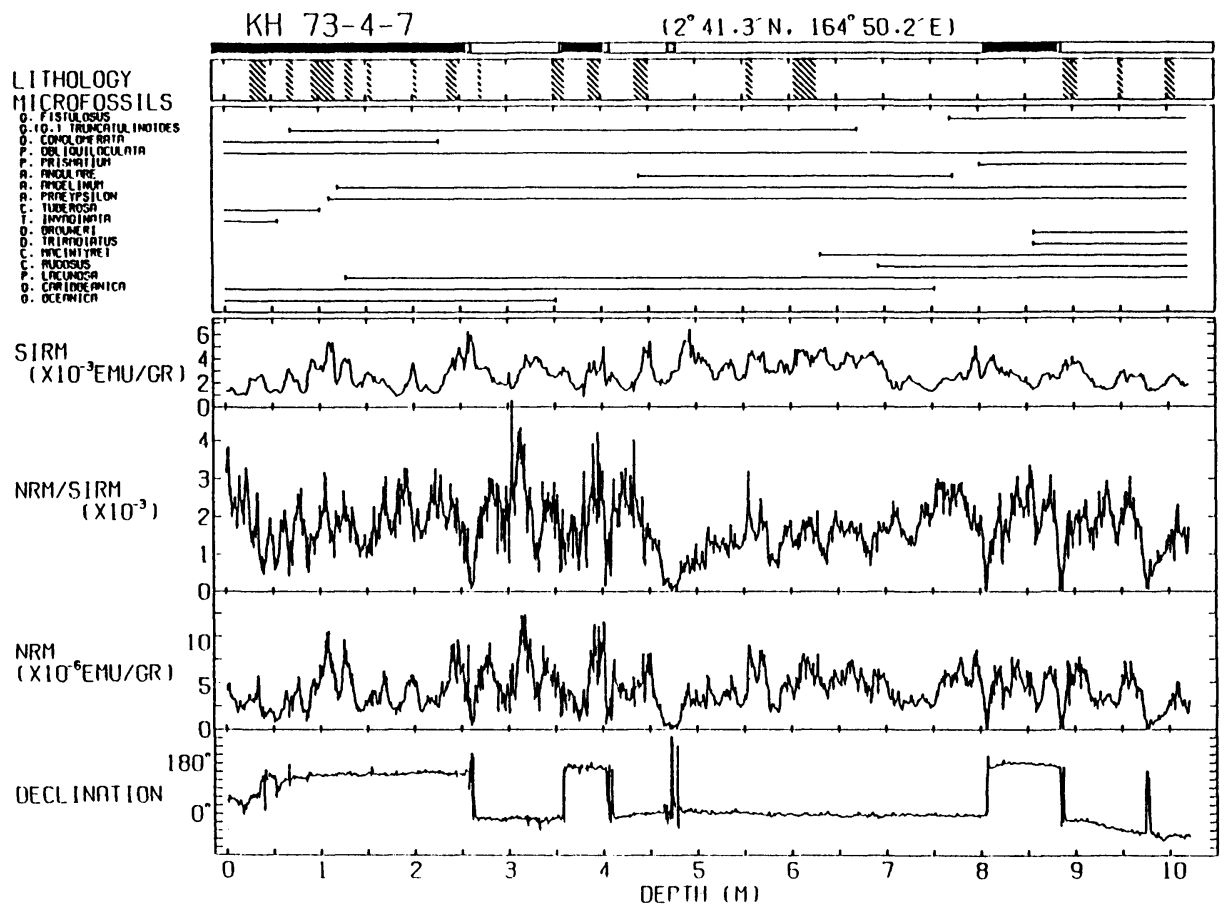

Fig. 4. Results of magnetic studies by KAWAI et al. $(1976,1977)$ and by SUEISHI et al. (1979) from core A. Faunal and floral stratigraphy are referred from the results by TAKAYANAGI et al. (1979). Dark portions observed in the core by KOBAYASH et al. (1980) are hatched in the column of lithology.

Electron spin resonance (ESR) study for dating foraminifera was done on these cores (SATO, 1982). Although it is necessary for precise dating to estimate the annual dose variation caused by disequilibrium of the U-decay chain and by the decrease in water content with the increase in the depth of the sediment, approximate ages are obtained from the total doses which are divided by the mean annual dose at the Brunhes-Matuyama boundary in each core (Fig. 6). On the basis of the ESR study, the age of the top of core $\mathrm{A}$ is correlated to the present. Fig. 6.

Ages determined by these methods were used to correlate the cores as shown in

\subsection{SIRM intensity}

As the fluctuations in the SIRM intensity have less high frequency components, we can easily examine whether correlative features of the fluctuations between the cores exist or not by assuming a suitable variation of the relative sedimentation rate within the framework of the magnetostratigraphic correlation. As shown in Figs. 5(a) and (b) (below), the correlation of the pattern of variations in intensity of SIRM between the two cores is remarkable good. We estimate the variation of the relative 
sedimentation rate in core $B$ by assuming the correspondences in the SIRM fluctuations at 14 depth levels shown in Fig. 5 with core A, and assuming constant sedimentation rates between the depths. The resemblance between the cores may depend on the number of the levels at which the correspondences are assumed. Although there is ambiguity in the estimation of the detailed variation of the relative sedimentation rate, the gap between the cores would be less than ten thousand years in most parts except for the portions in which correspondence does not appear. It should be noted that the fluctuation in SIRM is not only similar between the cores, but also the absolute values coincide with each other in the assumed variation of the sedimentation rate.

The cause of such a good correlation of SIRM between cores at reasonably separated sites is discussed elsewhere (SATO et al., 1988) from the viewpoint of the bacterial origin of magnetite contained in these cores. In the present article, the cause of the correlation is not discussed but the result is used to correlate cores.

\section{Long-Term Secular Variation in the Magnetic Field Intensity and Declination}

Variations in the ratio of NRM/SIRM in the two cores are also quite well correlated to each other as seen in Fig. 5 (middle). There are a few exceptions, such as portions younger than $0.2 \mathrm{My}$, between 1.3 and $1.55 \mathrm{My}$, and older than $1.9 \mathrm{My}$. It is understandable that the top and the bottom of each core were mechanically disturbed during the coring and extraction operations. For cores older than the Olduvai event, it is difficult to correlate the two cores, since the sedimentation rate of core B appears to be slower than that of core A by more than one order of magnitude but no reliable datum plane is available of core $B$.

It is remarkable that no detectable systematic discrepancy of the phase in the NRM/SIRM variation is observed between the two cores, although the sedimentation rates are quite different from each other, particularly in the internal between 0.2 and 0.7 My. In both cores, the variation in NRM/SIRM in the Olduvai event also resembles each other.

Fairly good correlation appears to exist in the relative declination, also. In particular, for the period of $0.38-0.70 \mathrm{My}$ in which significant swings in direction are seen in core $\mathrm{B}$, the correlation of the pattern of variation is still good, although the amplitudes of the oscillations are different between the cores.

NRM of sediment is believed to be acquired in an appreciable width of magnetizing zone, usually represented as a width in which only half a magnetic moment is fixed. Therefore, a decrease in amplitude of oscillation with a shorter wavelength is expected for magnetic records in sediments with lower rates of sedimentation. In other words, the process of acquisition of the remanent magnetization may be a high-cut filter. To test this proposition, we calculated the deconvoluted variations of declination, and of the intensity, using a moment fixing function of exponential (HAMANO, 1980; HYODO, 1984).

Amplitudes of the oscillation with periods longer than 20 thousand years are focused on in the present study, since the accuracy of correlation deduced from the 


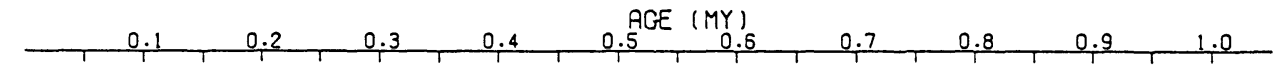

DEPTH (M) IN KH 73-4-8
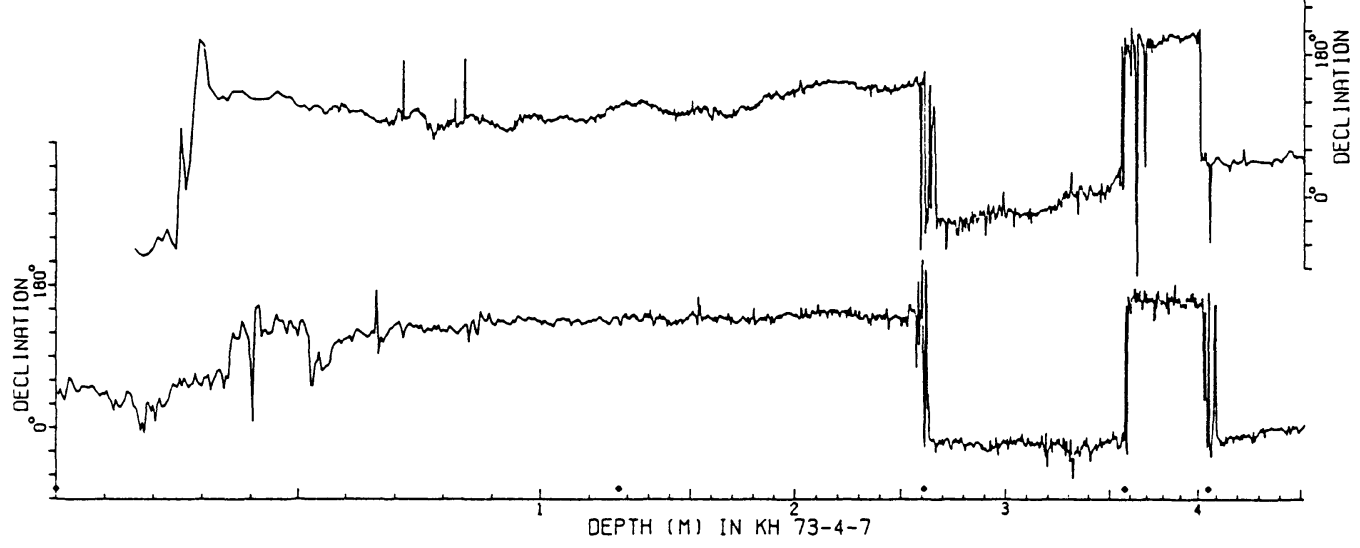

DEPTH (M) IN KH 73-4-8,
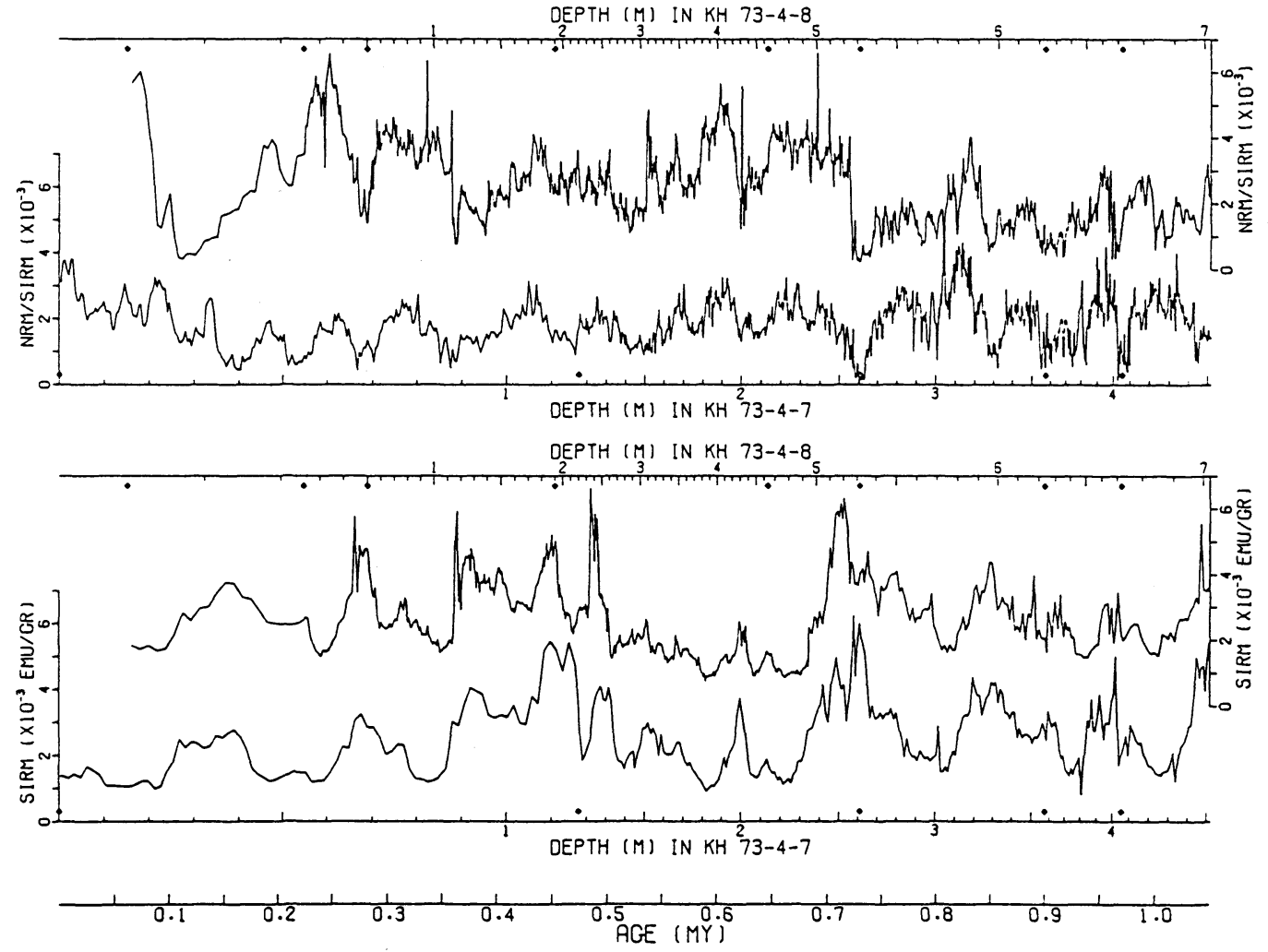

(a)

Fig. 5. 

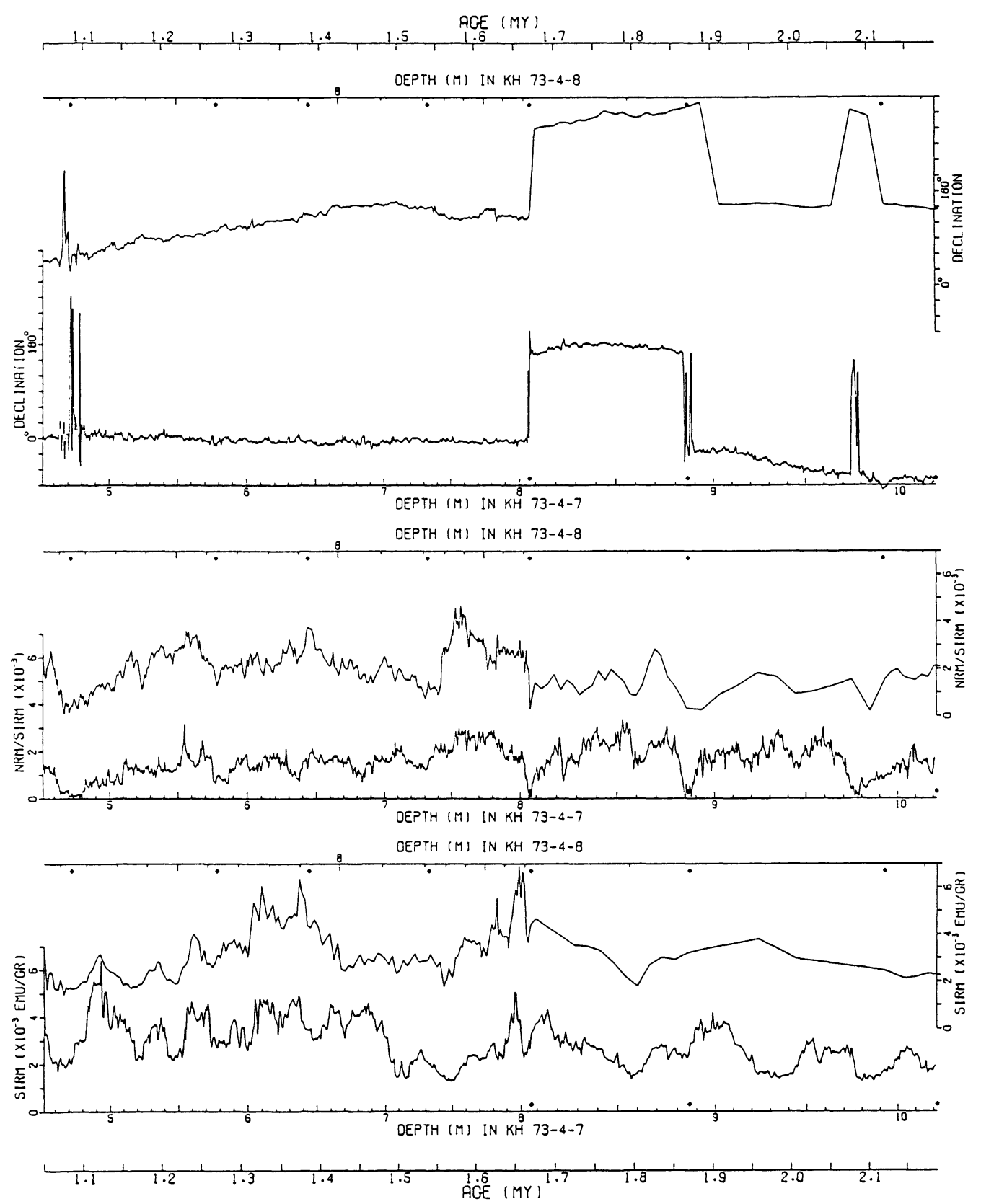

(b)

Fig. 5. Comparison of the variations of relative declination (upper), NRM/SIRM ratio (middle) and SIRM intensity (lower) between the cores. The depths at which the correlation of the SIRMintensity variations is assumed are indicated below the axis of depth in core B by $\$$. The depths at which the sedimentation rate in core $A$ is assumed to be changed are indicated above the axis of depth in core A by 


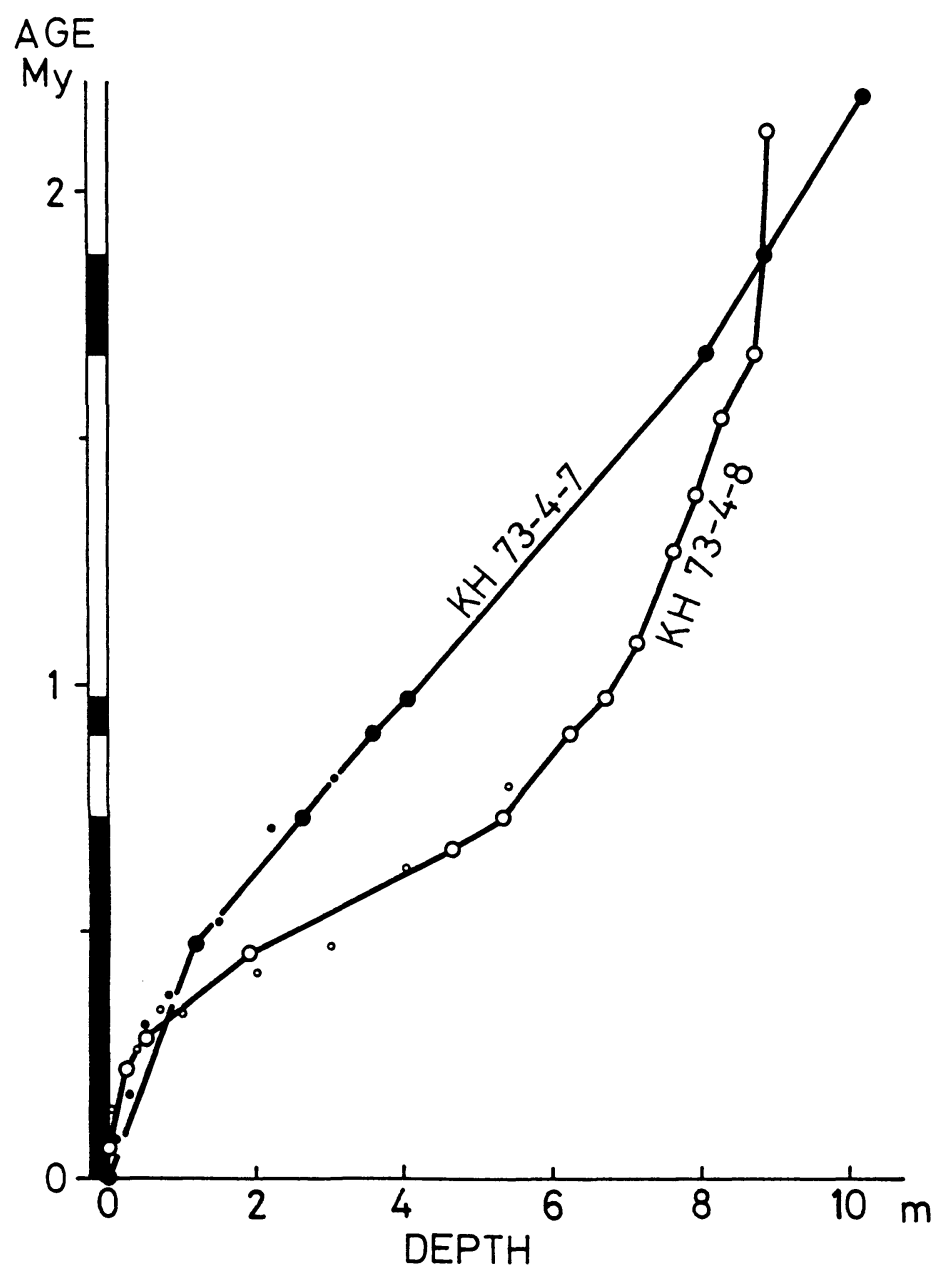

Fig. 6. Time versus depth plot for the cores. The sedimentation rate in core A is estimated by use of magnetostratigraphy and a datum plane of the last appearance of $P$. lacunosa $(0.474$ My by GARTNER, 1977) observed by TAKAYANAGI et al. (1979). The sedimentation rate in core B is estimated by the means mentioned above and by the correlation of SIRM intensity with core B. Results from the ESR study are also shown. The ages are calculated from the total doses (SATO, 1982) divided by the mean annual dose at the Brunhes-Matuyama boundary for cores A (small solid circle) and B (small open circle).

above methods is less than about ten thousand years. Series of declination data are detrended by a first-order polynomial with a mean value equal to zero and smoothed by the operation of a 5-point weighted running mean. The NRM/SIRM series is transformed to a function with a mean value of unity by detrending by a first-order polynomial and dividing by the mean of the original data, and smoothed 
in the same manner. The virtual geomagnetic secular variation was calculated from the sets of data smoothed by deconvolution for the several widths of the magnetizing zone, and followed by smoothing with an operation of running mean within a period of ten thousand years. For the calculation of declination, magnetic intensity is assumed to be constant and for NRM/SIRM, the magnetic direction is constant as an approximation.

As represented in Fig. 8(b), the amplitude of the intensity oscillation in a period of 0.37-0.52 My is larger in core A, even if the width is $2 \mathrm{~cm}$. If the width is $5 \mathrm{~cm}$, core A surpasses core B in the amplitude curve for the whole length of the period examined. The declination shows similar amplitude curves for both cores with the width of $2 \mathrm{~cm}$ (Fig. 8(a)). As the 5-points running mean operation generally causes a decrease in amplitude, particularly in sediment with low sedimentation rates, the width of the magnetizing zone seems to be shorter than $2 \mathrm{~cm}$.

In order to simulate amplitudes of the swing at $0.48 \mathrm{My}$ and the long-term oscilliation in the period of $0.52-0.67 \mathrm{My}$ in the declination of both cores, a width longer than $10 \mathrm{~cm}$ is needed for the magnetizing zone. However, such a long width causes inconsistent amplitudes in the other portions of the cores in declination and in the overall discrepancy in the intensity of the curves. A possible interpretation of this problem is that the long-term oscillation seen in $0.48-0.70 \mathrm{My}$ in core $\mathrm{B}$ is at least partly caused by mechanical twisting of core $B$, but does not reflect a real secular variation of the earth's magnetic field. Variable rates of the twisting of core $\mathrm{B}$, instead of the constant rate assumed, might cause the discrepancy.

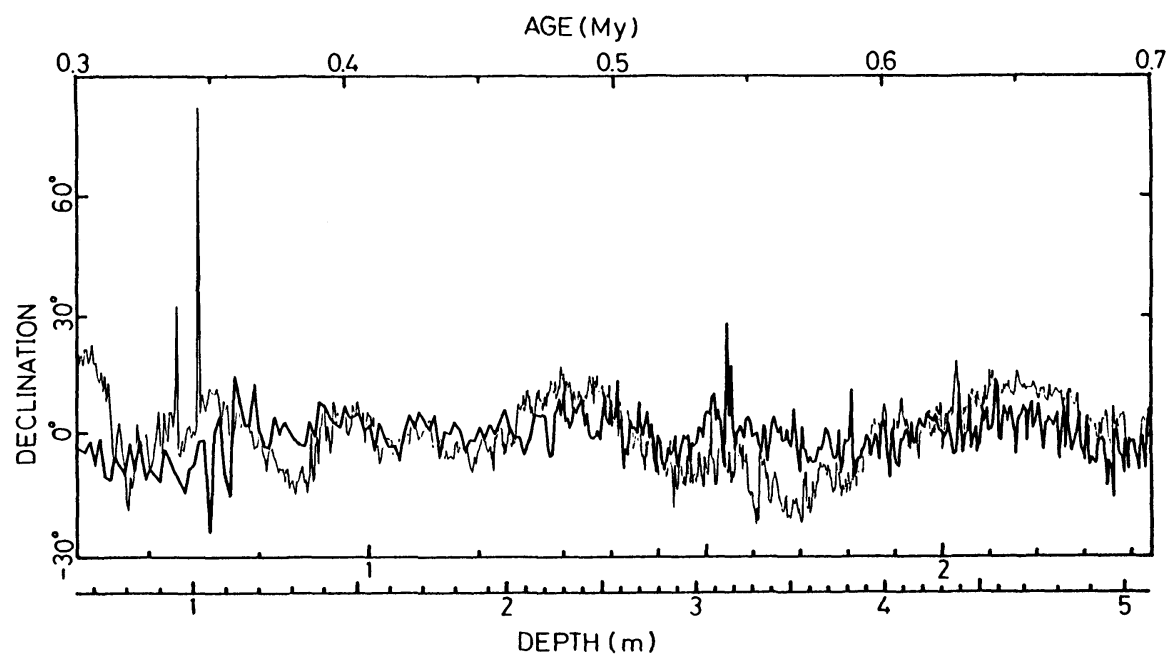

Fig. 7. Relative declination in cores $A$ (thick line) and B (thin line) versus ages assumed in Fig. 6 of a period of 0.3-0.7 My. The upper of the depth axes is for core A and the lower for core $B$. The declination variations are obtained by an operation of detrending with a first-order polynomial from the original data. 

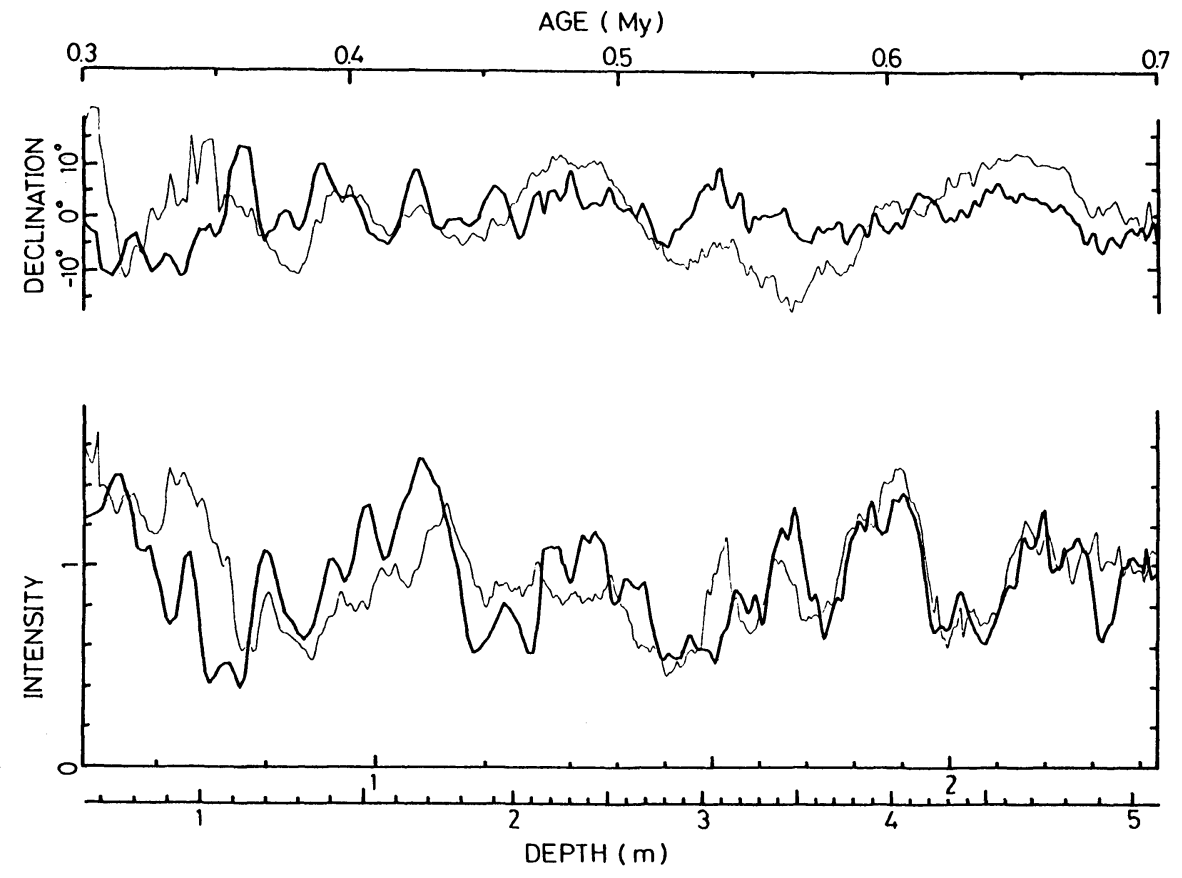

Fig. 8. Deconvoluted declination variations (upper) and deconvoluted NRM/SIRM variations (lower) for cores A (thick lines) and B (thin lines). The horizontal axes are the same as Fig. 7. The width of the magnetizing zone is $2 \mathrm{~cm}$ (see detail in the text).

In spite of such a slight disorder in core $B$, general coincidences in the phase of the oscillation, particularly in the period of $0.37-0.70 \mathrm{My}$, is quite apparent for both the declination and the intensity. Periods of the oscillation in both declination and intensity range from $0.02 \mathrm{My}$ to an order of $0.1 \mathrm{My}$. The widths of the magnetizing zone in the sediments are estimated to be sufficiently narrow enough to record the detailed paleomagnetic field variation. On the basis of these results, it can be concluded that the paleomagnetic records in the sediment cores reveal really longterm secular variations in the geomagnetic field direction and intensity.

It is widely assumed that the geomagnetic field behavior during a time interval longer than a characteristic one is a random time series that approximates an axial dipole. In other words, it can be said that the geomagnetic field is stationary if the time interval of the observation is longer than that of the characteristic one. The actual time interval required for the stationarity was estimated to be 10,000 years from late Quaternary lake sediments (LUND and BANERJEE, 1985). Whether the geomagnetism during late Quaternary is especially quasi-stationary, or whether the one during the early Brunhes epoch has exceptionally low frequency components remain to be solved in future work. In order to construct models for the long-term secular variation, it is necessary to know the areal extent of the applicability of the 
SIRM correlation and to obtain much more reliable paleomagnetism data from geographically separated sites within the areal extent.

This is a development of the work initiated by the late Prof. N. Kawai. The authors acknowledge the help of Prof. S. Sasajima of Hanazono University and Dr. M. Torii of Kyoto University in this work. Thanks are extended to Prof. S. Kume and Dr. A. Onodera for encouraging one of the authors (T.S.) during this study.

\section{REFERENCES}

Creer, K. M. and P. Tucholka, On the current state of lake sediment palaeomagnetic research, Geophys. J. R. astr. Soc., 74, 223-238, 1983.

GARTNER, S., Calcareous nannofossil biostratigraphy and revised zonation of the Pleistocene, Mar. Micropaleontol., 2, 1-25, 1977.

Hamano, Y., An experiment on the post-depositional remanent magnetization in artificial and natural sediments, Earth Planet. Sci. Lett., 51, 221-232, 1980.

Hyodo, M., Possibility of reconstruction of the past geomagnetic field from homogeneous sediments, $J$. Geomag. Geoelectr., 36, 45-62, 1984.

Kawai, N., Y. Otofuji, and K. Kobayashi, Paleomagnetic study of deep-sea sediments using thin sections, J. Geomag. Geoelectr., 28, 395-412, 1976.

Kawai, N., T. Sato, T. Sueishi, and K. Kobayashi, Paleomagnetic study of deep-sea sediments from the Melanesia basin, J. Geomag. Geoelectr., 29, 211- 223, 1977.

Kobayashi, K., S. Tonouchi, T. Furuta, and M. Watanabe, Paleomagnetic results of deep-sea sediment cores collected by the R. V. Hakuho Maru in a period 1968-1977 compiled with associated information, Bull. Ocean Res. Inst. Univ. Tokyo, No. 13, 1980.

Kulikova, L. S., The spectrum of the paleosecular variations of the geomagnetic field of the past 50 thousand years according to the data of the Molodova V and Korman' IV (Ukraine) sections, Geomag. Aer., 24, 641-645, 1984.

Lund, S. P. and S. K. BANERJEe, Late Quaternary paleomagnetic field secular variation from two Minnesota lakes, J. Geophys. Res., 90, 803-825, 1985.

SATo, T., ESR dating of planktonic foraminifera, Nature, 300, 518-521, 1982.

Sato, T., N. NAKaI, K. KobayAshi, and J. AKaI, Content of bacterial magnetite in deep-sea sediments as an indicator of organic productivity, Nature, 1988 (submitted).

Sueishi, T., T. Sato, N. Kawai, and K. Kobayashi, Short geomagnetic episodes in the Matuyama epoch, Phys. Earth Planet. Inter., 19, 1-11, 1979.

Takayanagi, Y., T. Takayama, T. Sakai, T. Oda, and M. Kato, Late Cenozoic micropaleontologic events in the equatorial Pacific sediments, Tohoku Univ. Sci. Rep., 2nd ser. (Geol.), 49, 71-87, 1979. 